\title{
Door to relocation time for dislocated hip prosthesis: multicentre comparison of emergency department procedural sedation versus theatre-based general anaesthesia
}

\author{
J Gagg, ${ }^{1}$ L Jones, ${ }^{1}$ G Shingler, ${ }^{2}$ N Bothma, ${ }^{3}$ H Simpkins, ${ }^{4}$ S Gill, ${ }^{5}$ J Benger, ${ }^{6}$ G Lloyd
}

${ }^{1}$ Emergency Department, Royal Devon and Exeter Hospital, Exeter, UK; ${ }^{2}$ Emergency Department, Frenchay Hospital, Bristol, UK; ${ }^{3}$ Emergency Department, Derriford Hospital Plymouth, UK; ${ }^{4}$ Emergency Department, Musgrove Park Hospital, Taunton, UK

${ }^{5}$ Emergency Department, Bristol Royal Infirmary, Bristol, UK;

${ }^{6}$ Academic Department of Emergency Care, University Hospitals Bristol NHS Foundation Trust, Bristol, UK

Correspondence to: Dr G Lloyd, Emergency Department, Royal Devon \& Exeter NHS Foundation Trust. Barrack Road, Exeter EX2 5DW, UK; gavin.lloyd@rdeft.nhs.uk

Accepted 11 September 2008

\section{ABSTRACT}

Background: Dislocation of a hip prosthesis is a painful event which has an incidence of $4 \%$ for primary total hip arthroplasty. Relocation is traditionally performed under general anaesthesia in the operating theatre, but relocation using sedation in the emergency department (ED) has been reported, with a limited success rate of $62 \%$. A study was undertaken to compare door to relocation times for $\mathrm{ED}$ sedation and theatre general anaesthesia.

Methods: The notes of all patients attending five centres in the south west of England with prosthetic hip dislocation over a 12-month period between 2005 and 2006 were retrospectively reviewed using standardised data collection forms.

Results: Successful ED reduction was significantly quicker than failed ED reduction and theatre-based general anaesthesia (2 h 21 min vs 8 h 32 min; $\mathrm{p}<0.001)$. No statistical difference was found between failed ED reduction and theatre general anaesthesia.

Conclusions: Reduction of dislocated hip prostheses in the ED saves nearly $6 \mathrm{~h}$ compared with theatre-based general anaesthesia and is therefore advocated.

Dislocation of a hip prosthesis is a painful event which has an incidence of $4 \%$ for primary total hip arthroplasty. ${ }^{1}$ Relocation is traditionally performed under general anaesthesia in the operating theatre. Relocation using sedation in the emergency department (ED) has been reported previously, ${ }^{2}$ with a limited success rate of $62 \%$. The same paper reported a mean time for attempted ED relocation of $1.83 \mathrm{~h}$ compared with $10.9 \mathrm{~h}$ for general anaesthesia in the theatre. Early relocation reduces the time that a patient is required to wait in discomfort for definitive treatment.

We wished to explore whether the reported delay was common to other centres. Our primary objective was therefore to compare door to relocation times for sedation in the $\mathrm{ED}$ and general anaesthesia in the theatre. Secondary objectives were to identify:

- whether the service provided in each hospital was different;

- whether unsuccessful attempts at reduction in the ED result in significant delay compared with general anaesthesia in the theatre without reduction in the $\mathrm{ED}$;

- relocation success rates in the ED for each centre and collectively;

- drugs used for sedation in the ED and their association with relocation success.

\section{METHODS}

Data were collected from five centres in southwest England: Bristol Royal Infirmary (BRI), Derriford Hospital, Frenchay Hospital, Musgrove Park Hospital (MPH) and Royal Devon \& Exeter (RD\&E) Hospital. One researcher in each centre retrospectively reviewed the notes of all patients attending with prosthetic hip dislocation over a 12month period between 2005 and 2006 Standardised data collection forms were used Statistical analysis found time to be log normal and was modelled using a fixed and random effects model in which centre was fitted as a random effect and procedure fitted as a fixed effect. A Scheffe post hoc test was used to investigate where statistical significance lay when procedure type was found to be statistically significant.

\section{RESULTS}

Complete data were available for 165 of the 202 patients identified; 37 patients were excluded from the study (no arrival time recorded for 2, no ED sedation time recorded for 20 , no theatre general anaesthesia time recorded for 12, and 3 with inadequate data for analysis).

The results for individual centres and collective data are shown in table 1 . Successful ED reduction was significantly quicker than both failed reduction in the ED and general anaesthesia in the theatre $(p<0.001)$. No statistical difference was found between failed ED reduction and general anaesthesia in the theatre $(p=0.53)$.

Table 2 shows the sedative strategy used at each centre. Midazolam and propofol were the only sedatives recorded, with a success rate of $64 \%$ and $96 \%$, respectively. In eight cases the sedative was not recorded.

\section{DISCUSSION}

This study demonstrates a clear benefit to patients in terms of successful relocation in the ED compared with general anaesthesia in the theatre, saving the patient nearly $6 \mathrm{~h}$ of discomfort ( $8 \mathrm{~h} 10 \mathrm{~min}$ versus 2 h 21 min). Furthermore, a failed ED reduction does not delay the final reduction in theatre.

Only one centre (Derriford) did not attempt ED reduction in the majority of patients. On further enquiry the decision regarding $\mathrm{ED}$ reduction is made by the duty emergency physician. Two centres (Frenchay and RD\&E) offered propofol sedation in the ED to some patients, although the 
Table 1 Door to relocation time for dislocated hip prostheses (median and geometric mean times displayed in hours and minutes)

\begin{tabular}{|c|c|c|c|c|c|c|c|c|c|c|c|c|}
\hline & \multicolumn{2}{|l|}{ BRI } & \multicolumn{2}{|l|}{ Derriford } & \multicolumn{2}{|l|}{ Frenchay } & \multicolumn{2}{|l|}{ MPH } & \multicolumn{2}{|l|}{ RD\&E } & \multicolumn{2}{|l|}{ Collectively } \\
\hline & $\begin{array}{l}\text { Median } \\
\text { (mean) }\end{array}$ & $\mathbf{n}$ & $\begin{array}{l}\text { Median } \\
\text { (mean) }\end{array}$ & $n$ & $\begin{array}{l}\text { Median } \\
\text { (mean) }\end{array}$ & $\mathbf{n}$ & $\begin{array}{l}\text { Median } \\
\text { (mean) }\end{array}$ & $\mathbf{n}$ & $\begin{array}{l}\text { Median } \\
\text { (mean) }\end{array}$ & $\mathbf{n}$ & $\begin{array}{l}\text { Median } \\
\text { (mean) }\end{array}$ & $n$ \\
\hline ED reduction & $\begin{array}{l}3 \text { h } 52 \text { min } \\
\text { (2 h } 49 \text { min) }\end{array}$ & 14 & $\begin{array}{l}2 \text { h } 46 \min \\
\text { (2 h } 45 \mathrm{~min})\end{array}$ & 13 & $\begin{array}{l}2 \text { h } 31 \text { min } \\
\text { (2 h } 15 \mathrm{~min})\end{array}$ & 20 & $\begin{array}{l}1 \text { h } 44 \min \\
\text { (1 h } 49 \mathrm{~min})\end{array}$ & 12 & $\begin{array}{l}2 \text { h } 1 \text { min } \\
\text { (1 h } 51 \mathrm{~min})\end{array}$ & 33 & $\begin{array}{l}2 \text { h } 21 \mathrm{~min} \\
(2 \mathrm{~h} 10 \mathrm{~min})\end{array}$ & 92 \\
\hline $\begin{array}{l}\text { Failed ED reduction, then } \\
\text { theatre GA }\end{array}$ & $\begin{array}{l}7 \text { h } 12 \min \\
\text { (6 h } 52 \mathrm{~min})\end{array}$ & 7 & $\begin{array}{l}6 \text { h } 14 \mathrm{~min} \\
\text { (7 h } 50 \mathrm{~min})\end{array}$ & 10 & $\begin{array}{l}11 \text { h } 20 \mathrm{~min} \\
\text { (11 h } 40 \mathrm{~min})\end{array}$ & 10 & $\begin{array}{l}7 \text { h } 5 \text { min } \\
\text { (6 h } 48 \mathrm{~min})\end{array}$ & 9 & $\begin{array}{l}12 \text { h } 38 \mathrm{~min} \\
(14 \text { h } 9 \mathrm{~min})\end{array}$ & 7 & $\begin{array}{l}8 \text { h } 32 \mathrm{~min} \\
\text { (9 h } 0 \mathrm{~min})\end{array}$ & 43 \\
\hline $\begin{array}{l}\text { No attempt at ED reduction } \\
\text { (theatre GA only) }\end{array}$ & $24 \mathrm{~h} 32 \mathrm{~min}$ & 1 & $\begin{array}{l}8 \mathrm{~h} 10 \mathrm{~min} \\
(7 \mathrm{~h} 19 \mathrm{~min})\end{array}$ & 22 & $\begin{array}{l}19 \text { h } 52 \mathrm{~min} \\
\text { (11 h } 27 \mathrm{~min})\end{array}$ & 3 & $4 \mathrm{~h} 16 \min$ & 1 & $\begin{array}{l}5 \text { h } 24 \mathrm{~min} \\
\text { (5 h } 40 \mathrm{~min})\end{array}$ & 3 & $\begin{array}{l}8 \text { h } 10 \mathrm{~min} \\
(7 \mathrm{~h} 38 \mathrm{~min})\end{array}$ & 30 \\
\hline
\end{tabular}

BRI, Bristol Royal Infirmary; ED, emergency department; GA, general anaesthetic; MPH, Musgrove Park Hospital; RD\&E, Royal Devon \& Exeter Hospital.

Table 2 Success/failure data for reduction of dislocated hip prostheses in ED by drug used

\begin{tabular}{lllllllll}
\hline & & BRI & Derriford & Frenchay & MPH & RD\&E & Collectively & Success rate (\%) \\
\hline Midazolam & Success & 11 & 13 & 9 & 11 & 23 & 67 & 64 \\
\multirow{3}{*}{ Propofol } & Failure & 5 & 8 & 10 & 9 & 5 & 37 & 22 \\
\multirow{3}{*}{ Not recorded } & Success & 1 & 0 & 11 & 0 & 9 & 1 & 96 \\
& Failure & 0 & 0 & 0 & 0 & 1 & 3 & 38 \\
& Success & 2 & 0 & 0 & 0 & 1 & 5 \\
\hline
\end{tabular}

BRI, Bristol Royal Infirmary; ED, emergency department; MPH, Musgrove Park Hospital; RD\&E, Royal Devon \& Exeter Hospital.

selection criteria were not explored. The collective success rate for relocation with midazolam (64\%) is in keeping with published experience. ${ }^{2}$ The apparently superior performance with propofol $(96 \%)$ is considered in our companion paper. ${ }^{3}$

This study is a retrospective chart review. The quality of the data collected is limited by both the precision of the original records and the extraction process. The information was extracted from the records by one individual in each centre, and this was not independently verified. The individuals collecting the data were aware of the aims of the study, which could have introduced bias.

Although these comparative data are interesting, our retrospective methodology considers association rather than causation. It seems likely that factors mitigating against sedation in the ED (such as profound patient co-morbidity) will also delay general anaesthesia in the theatre. Similarly, patients suitable for propofol sedation may be a group in whom relocation is technically easier for reasons other than the choice of sedative drug. Further prospective study, perhaps in the form of a randomised trial, is required to establish whether sedation with propofol in the ED is the optimal management strategy in this patient group.

\section{CONCLUSIONS}

Reduction of dislocated hip prostheses in the ED saves nearly $6 \mathrm{~h}$ compared with theatre-based general anaesthesia and is therefore advocated.

Acknowledgements: The authors thank Jason Smith, lan Higginson, Jason Kendall and Clifford Mann for supervising the study in their respective hospitals.

Competing interests: None declared.

Ethics approval: The local research ethics committee did not require formal review of this study.

Contributions: JG collated and analysed the raw data and co-wrote the paper. GS, $\mathrm{NB}, \mathrm{HS}$ and SM collected the data from their respective emergency departments. LJ and JB advised and helped supervise the study; JB edited the paper. GL had the original idea, supervised the study, co-wrote the paper and acts as guarantor.

\section{REFERENCES}

1. Phillips CB, Barrett JA, Losina E, et al. Incidence rates of dislocation, pulmonary embolism and deep infection during the first six months after elective hip replacement. J Bone Joint Surg Am 2004;85-A:20-6.

2. Fryman SJ, Cumberbatch GLA, Stearman ASL. Reduction of dislocated hip prosthesis in the emergency department using conscious sedation: a prospective study. Emerg Med J 2005;22:807-9.

3. Mathieu N, Jones L, Harris A, et al. Is propofol a safe and effective sedative for relocating hip prostheses? Emerg Med J 2009;26:37-38. 